\title{
Prospects for China's economic development in the next decade
}

\author{
Shantong $\mathrm{Li}^{1 *}$, Sanmang $\mathrm{Wu}^{2}$ and Jianwu He
}

\author{
* Correspondence: \\ shantong@drc.gov.cn \\ ${ }^{1}$ Department of Development \\ Strategy and Regional Economy, \\ Development Research Center of \\ the State Council, No. 225, Chaonei \\ Dajie, Beijing 100010, China \\ Full list of author information is \\ available at the end of the article
}

\begin{abstract}
This article discusses prospects for China's economic development over the next decade based on the computable general equilibrium (CGE) model of the Chinese economy. The article argues that the long-term trend of China's economy will remain positive and the major driving forces of the fast-growing Chinese economy still exist. However, particular focus must be placed on the changes in the domestic and international environment in the next decade. Further reforms should be promoted in the field of economic elements, public expenditure, energy, and the environment in order to improve the sustainability and balance of economic development.
\end{abstract}

Keywords: China's economy; Review; Prospects

The decade from 2001 to 2010 was a 'golden decade' for China's economic development. China's growth stabilized, with $10.5 \%$ gross domestic product (GDP) growth on average; China followed the trend of the international division of industries, encouraged foreign trade, and promoted two-way investment. With the increase of China's comprehensive national power, it has become the second largest economy in the world and the largest contributor to world economic growth with a contribution of $18.3 \%$. The industrial structure improved over the decade with the structure of three industries being 10.1:46.8:43.1 in 2010, compared to 14.4:45.1:40.5 in 2001.

In general, China's economic growth has benefited from a favorable international environment ( $\mathrm{Hu}$ et al. 2011; Pei and Yang 2011). China's accession to the World Trade Organization (WTO) in 2001 has promoted the integration of China's comparative advantages, such as factor costs, with a relatively favorable international environment (Li et al. 2010). China's economy has been in a new period of growth in the early twenty-first century. Reforms to the economic system have promoted economic efficiency while accelerated urbanization has driven economic growth and an upgraded consumption structure has injected growth into China's economy. These are the fundamental causes for China's development in the 'golden decade'.

What are the prospects for China's economic development in the next decade? Currently, with the ongoing, deep impact of the international financial crisis, the world economy will remain in a period of rebalancing, and the Chinese economy is showing a number of characteristics of this new stage. This article gives a systematic overview of the evolution of the domestic and international environment and offers analysis in this regard by using the computable general equilibrium model of the Chinese economy from the State Council's Development Research Center (DRC-CGE).

(c) 2013 Li et al.; licensee Springer. This is an Open Access article distributed under the terms of the Creative Commons Attribution License (http://creativecommons.org/licenses/by/2.0), which permits unrestricted use, distribution, and reproduction in any medium, provided the original work is properly cited. 


\section{The international environment for China's economic development in the next decade}

The recovery of world economy remains a hard and torturous process, and the world is entering a period of moderate- and low-speed growth

Despite the better-than-expected recovery of the world economy since 2010, the unemployment rate in the USA, Japan, and EU remains high; consumer confidence in the economy is recovering slowly; and the property market and private economy have yet to fully restart, with a slower pace of inventory adjustment continuing. The sovereign debt crisis in some European countries has led to market turmoil, hindering the recovery of countries there. The slow economic recovery in the USA, Japan, and EU has added to the uncertainties in the recovery of the world economy. In the meantime, the endogenous power for the recovery of the world economy is insufficient. Developed countries have suffered the international financial crisis with economic recession, sluggish credit growth, and deteriorating fiscal conditions, which has restricted their ability to stimulate economic growth with credit and fiscal expansion.

The upcoming global economic rebalancing will lead to remarkable changes in the global supply and demand structure

The international financial crisis has dealt a major blow to the former pattern of global economic development. The financial crisis proves that the development pattern featuring excessive consumption in countries like the USA is unsustainable and the development pattern of some developing countries and emerging markets, which overly relies on exports to countries featuring excessive consumption, will be difficult to sustain. The upcoming global economic rebalancing will lead to remarkable changes in the global supply and demand structure. In terms of supply, major developed countries will further promote exports and rejuvenate their domestic manufacturing industries, make efforts to lead technological innovation and development of new industries, and encourage the upgrading of industries. Emerging economies and developing countries will accelerate the development of industries and technologies in which they have comparative advantages. In terms of demand, the factors that stimulated consumption in developed countries will weaken. The citizens in developed countries will change their consumption behavior and increase savings. Therefore, their problems of excessive consumption and insufficient investment will be adjusted with less demand for imports, while developing countries will need to secure other external demand and encourage domestic demand.

\section{Economic globalization will not be reversed, but trade protectionism will gain ground}

The international financial crisis has had multiple negative impacts on economic globalization, such as the deceleration of trade growth, a stronger tendency toward protectionism, strengthened fiscal regulation, and slower international capital flows. Developing countries are taking a more prudent attitude toward the liberalization of financial markets, and difficulties are growing in multilateral trade negotiation (the Doha Round of trade talk, for example). Therefore, the process of economic globalization will face periodic adjustment due to the international financial crisis 
(Lu 2010). In the future, with the restrictive power of the WTO's multilateral trade system, its rules and dispute resolution system will still be in effect. National interventionism and trade protectionism will not become the mainstream, and economic globalization will not be reversed (Long 2011). But we must notice that it will take time to restore international demand, which has contracted significantly due to financial crisis, to normal levels. Meanwhile, there is still significant overcapacity for production, and various forms of trade and investment protectionism are still on the rise.

\section{Global issues like climate change and energy and resource security will become more prominent}

Green and sustainable development has become a common concern for all countries. It has been a focus in the international political game and economic and technological competition to address climate change. Constrained by its development stage and level technological advancement amid fast industrialization and urbanization, developing countries have a stronger reliance on traditional energy and resources, which in Western countries have brought them pressures from environmental costs, rising energy prices, and public opinion. To address climate change, the international financial crisis, and the rising cost of traditional energy, developed countries and multinational companies have made preemptive and strategic arrangements and raised technological input substantially, in attempts to take early advantage in areas related to the low-carbon economy, such as new energy technologies, energy conservation, and emission reduction. The ideas and mechanisms proposed by developed countries, such as carbon trading and carbon tariffs, are partly positive and reasonable but are also intended to some extent to contain developing countries. Countries have had a stronger consensus on common efforts to address issues like climate change and energy and resource security but will have long-standing disputes on responsibility and obligations, development interests, economic transformation patterns, as well as technological and financial aid.

\section{The domestic environment for China's economic development in the next decade}

China is moving from an upper middle-income country to a high-income country The per capita GNI of China reached US\$4,270 in 2010. China is among the upper middle-income countries according to the World Bank's division of countries by using the criterion of per capita income. The next decade is a critical period for China to move from an upper middle-income country to a high-income country. However, international experience shows that the road from middle-income country to a high-income country is never a smooth one as the countries have been faced with double pressures from industrial competition with developed countries and underdeveloped countries. On one hand, low-income underdeveloped countries, which are their competitors, will be leading players in developed industries, bringing challenges to upper middle-income countries. On the other hand, developed countries, which are innovators, have possessed great advantages in the industries with rapid technological changes, and they are very difficult for upper middle-income countries to compete with. 
The cost of the factors that drive economic growth will experience critical changes, while the comparative advantage of cost will be weakened

First of all, the labor force will approach the Lewisian Turning Point, weakening the comparative advantage of labor cost. Moreover, the costs of factors of production, land for example, will rise rapidly. Last but not the least, the insufficiency of strategic resource reserves (including water resources, mineral resources and energy) and environmental capacity will further constrain economic development. China has a huge population, and the per capita possession of the resources is low, imposing severe constraints on economic development in terms of resources and the environment. China will be faced with difficulties in energy supply, production and transportation capacity, and environmental capacity for waste gas emissions.

The savings rate in China will gradually decrease, while the growth pattern of 'high saving rate and high investment rate' will be adjusted

Reviewing China's economic growth over the past three decades, rapid capital accumulation and capital deepening driven by the 'high saving rate and high investment rate' growth pattern have played very important roles. However, with the overall dependency ratio rising rapidly in the next decade, China's high savings rate will decrease, while adjustment must be made to the 'high saving rate and high investment rate' growth pattern.

The proportion of non-agricultural industry exceeds $90 \%$ with mounting pressure to upgrade the industrial structure

Since the launch of reform and opening, remarkable progress has been achieved in industrialization and industrial transfer in China. The proportion of non-agricultural added value was nearly $90 \%$, which has confirmed the dominance of industry among the three sectors. There will be only limited room for increases to non-agricultural industry and industrial transfer. China urgently requires the transformation and upgrading of its non-agricultural industries, especially the manufacturing industry. China's economic growth, which was driven by industry and increase in quantity, should be transformed to be driven by the coordination of three industrial sectors and the optimization and upgrading of their internal structures.

There remains plenty of room for urbanization, but the structure of the urban-rural relationship is undergoing major changes as permanent urban residents will account for over $50 \%$ of the entire population

With rapid urbanization in recent years, the proportion of the urban population has been increasing rapidly, reaching $49.6 \%$ in 2010. However, international experience shows that the peak of urbanization can be as high as $65 \%$ to $80 \%$. Therefore, there remains plenty of room in the next 10 to 20 years for China to promote urbanization, which will remain an important driving force for China's economic development. However, we must be aware of the fact that permanent urban residents will account for over $50 \%$ of the entire population, which reflects the imperative to improve the social welfare system, adjust the social policy system in urban areas, and improve the structure of urban governance. 
China is entering a period of outstanding social contradictions with a more pressing need to strengthen social management and find innovative solutions

At present, there is a significant gap between urban and rural areas and among different regions and social groups. The income gap has not shown any sign of narrowing, with the Gini coefficient exceeding 0.4. In the meantime, despite the development of social construction and progress made in various social undertakings, given the constraints of the current development stage, policies, and the social system, some of the issues that concern people's fundamental interests have not been truly addressed. Therefore, it is increasingly urgent to strengthen social management and find innovative solutions, safeguard social order, promote social harmony, ensure people's good living, and create a favorable social environment.

Energy and resource constraints are becoming more challenging with more pressure on the transformation of the model of economic development

Over the last three decades, China has adopted an 'investment-driven and industry first' model of economic development, which has supported long-term and high-speed economic growth but has also led to sharp increases in energy consumption and pollution with increasingly grave resource and environment problems. With the growing size of the economy, China will be faced with more acute constraints on the factors of production that are not directly traded, such as water, land, and the ecological environment. Moreover, the international community has higher expectations on China's responsibilities in the management of resources and environment issues. These facts show that China's economy will face more energy and environment constraints and there will be more pressure to transform the model of economic development.

\section{China's economic development prospects in the next decade}

Scenarios design for China's economic development prospects in the next decade

This article gives two scenarios to reflect the possible prospects for China's economic development (Table 1). One scenario is BAU or business as usual, which means that China's economy will follow the same model as in the past. The other one is 'accelerated reform', in which focus is placed on reforms in the market for factors of production, public expenditure, energy and the environment, and the service sector. Some typical measures will be implemented to promote reform, which will boost the reasonable flow of factors of production, promote economic efficiency, and address problems like overdependence on energy and resources and lagging development in the service sector.

Analysis of simulation results on China's economic development in the next decade Economic activities are complicated and interlinked with each other. The opportunities and challenges for the Chinese economy as mentioned above affect each other. In this sense, we need a complete and systematic economic model to analyze the scenarios of China's future economic development. We adopt the computable general equilibrium model of the Chinese economy from the State Council's Development Research Center (DRC-CGE) in our investigation. The model is recursive and dynamic and simulates the dynamic features of economic development by solving static equilibrium problems. 
Table 1 Scenario design for China's economic development in the next decade

Type of scenario BAU

Accelerated reform

\section{Scenarios}

1. The development trend of population size becomes exogenous, and the population projection from the United Nations is adopted

2. The urbanization level and urban and rural populations become exogenous with the urbanization rate increasing by 0.8 on average from 2010 to 2020

3. The growth of the aggregate labor force and changes in rural land supply become exogenous

4. Domestic tax rates remain unchanged, and transfer payments become exogenous

5. International payments tend to be balanced from 2010 to 2020

6. The growth rate of government consumption becomes exogenous

7. Total factor productivity (TFP) becomes exogenous, assuming that, from 2010 to 2020, the growth rate of TFP will decrease from the average level of the past 25 years

8. Biased technological progress and changes in the intermediate input rate become exogenous

9. Global economy remains depressed in the next decade but ultimately recovers gradually

1. Promote reform in energy and environment tax, perfect the price formation mechanism of resource products, and improve the efficiency of energy and resource utilization

$\gg$ The resource tax rate increases by $10 \%$ from the BAU level during the 12th Five-Year Plan

$\triangle \mathrm{A}$ carbon tax is imposed with tax rate increasing from $10 \mathrm{RMB}$ to 50 $\mathrm{RMB}$ per tonne of $\mathrm{CO}_{2}$. Income from carbon tax is mainly used as incentives to encourage enterprises to promote energy efficiency and innovate in the high-tech industry

$\triangleright$ The average efficiency utilization rate between 2010 and 2020 is $1 \%$ higher than the BAU level

2. Adjust the structure of public expenditures, moderately reduce construction expenditures, and perfect the social welfare system

$\triangleright$ The growth rate of government spending is slightly higher than the BAU level

3. Increase government investment in education, medical services, scientific research, and social welfare

$>$ Increase government transfer payments to poor regions and people by $10 \%$ from the BAU level from 2010 to 2020

4. Eliminate the barriers to the flow of labor between urban and rural areas or among different regions and industries, accelerate the urbanization process and citizenization of migrant workers, and promote quality urbanization

$>$ The urbanization rate increases by $0.25 \%$ annually based on the BAU level from 2010 to 2020 and the transfer of the urban and rural labor force is accelerated

5. Promote the reform of state-owned enterprises and monopoly industries and adjust the distribution system of state-owned enterprises and monopoly enterprises

$>$ Increase the payout ratio of SOE returns by 30\% from 2010 to 2020 in a progressive manner for public expenditure

6. Improve reform of service sector regulations, expand the scope of the value-added tax, and reduce the tax burden on the service sector

$\triangleright$ Reduce the tax on the service sector by $10 \%$ in a progressive manner

$\triangleright$ Eliminate the price difference between the service sector and industry in terms of electricity, water, gas, and heat

7. Promote reform to factors of production like land and capital, improve the efficiency of the utilization and allocation of such factors, boost technological innovation, and accelerate technological progress

$>$ Eliminate discrimination against various companies in the acquisition of factors of production like land and capital

$>$ TFP growth rate is higher than the BAU level by $0.2 \%$, while TFP in the service sector is higher than the BAU level by $0.6 \%$ 
The period of simulation is set to be from 2011 to 2020. For more details on the model, see Li et al. (2011) and Research Group on the Analysis and Application of Input-output Table of China in 2007 (2011).

\section{$B A U$ scenario analysis}

According to the assumptions of the BAU scenario, China will maintain its high economic growth rate. With the current momentum of economic growth, China's GDP will grow by $8.5 \%$ annually during the 12 th Five-Year Plan period and $7.0 \%$ annually from 2016 to 2020 (Table 2).

With regard to the sources of economic growth, the main driving force for China's economic growth from the beginning of the 12th Five-Year Plan to 2020 still lies in capital accumulation, which will contribute over 70\% of GDP growth. During the period of the 12th Five-Year Plan, China's GDP will increase by $8.5 \%$ annually on average, of which 6.4 percentage points will come from investment, accounting for $75 \%$ of the GDP growth rate. From 2016 to 2020, investment will drive 5.1 percentage points of economic growth or $72.8 \%$. Compared to capital, the increase in the labor force will contribute little to economic development with its contribution being close to zero. The contribution of total factor productivity (TFP) will grow from $22 \%$ during the 12 th Five-Year Plan to around 28\% in 2020.

As for the size of the economy, China's GDP will reach 58.71 trillion RMB (US $\$ 8.7$ trillion) in 2015, the end of 12th Five-Year Plan period, based on 2010 prices. By 2020, China's GDP will reach 82.45 trillion RMB (12.2 trillion USD). In terms of GDP per capita, China's GDP per capita is close to US\$5,000 in 2012 and will exceed US\$5,000 (US $\$ 5,371$ ) in 2015 and surpass US $\$ 8,000$ by 2020.

With regard to demand structure, the general savings rate will decrease. With the stimulus during financial crisis phasing out, the investment rate will return to its normal level in the next decade and then continue to decrease. International trade tends to be balanced with rising cost of factors like labor and land. A lower trade deficit and investment rate and an increased urbanization level and household income will lead to a higher proportion of consumption. The simulation results show that household consumption will account for $42 \%$ of GDP, while government spending will account for $15 \%$. The two items add up to $55 \%$, but the proportion of household consumption will increase to $46 \%$ by 2020 . However, despite this development model, the percentage of consumption in China's GDP in 2020 will still be lower than that of other countries at the same level of development.

Table 2 Economic growth and its sources in 2010 to 2020 (\%, BAU)

\begin{tabular}{lccc}
\hline Main variables & $\mathbf{2 0 1 1}$ to $\mathbf{2 0 1 5}$ & $\mathbf{2 0 1 6}$ to $\mathbf{2 0 2 0}$ & $\mathbf{2 0 1 1}$ to $\mathbf{2 0 2 0}$ \\
\hline GDP growth rate & 8.5 & 7.0 & 7.7 \\
Labor force growth rate & 0.5 & 0.0 & 0.2 \\
Capital growth rate & 10.7 & 8.5 & 9.6 \\
TFP growth rate & 1.9 & 1.9 & 1.9 \\
Labor force & 0.2 & 0.0 & 0.1 \\
Capital & 6.4 & 5.1 & 5.7 \\
TFP & 1.9 & 1.9 & 1.9 \\
\hline
\end{tabular}

Source of data: computational results of the DRC-CGE model. 
In terms of the industrial structure, the proportions of primary and secondary industry in the BAU scenario have been decreasing, while that of tertiary industry is on an upward trend. The proportion of primary industry in China will drop to $7.8 \%$ by 2015 and $5.9 \%$ by 2020 . The proportion of tertiary industry will rise to $43.8 \%$ by 2015 and continue to increase by $3 \%$ annually from 2015 to 2020 but remain low compared to the level common to other countries.

The adjustment of the industrial structure will lead to relevant changes in the employment structure. During the 12th Five-Year Plan period and by 2020, the labor force will shift from an agricultural to a non-agricultural industry. The proportion of employment in the primary industry will drop to $33.8 \%$ by the end of the 12th Five-Year Plan and $28 \%$ by 2020 . In contrast, the urbanization rate will rise, reaching $54 \%$ in 2015 and $58 \%$ by 2020 .

With rapid economic growth, household income will increase accordingly. In the BAU scenario, by the end of the 12th Five-Year Plan, the net income per capita of urban residents will reach 34,200 RMB, 70\% higher than the level in 2007, while net income per capita of rural residents will exceed 7,300 RMB, nearly $60 \%$ higher than in 2007 . However, with a growing income gap between urban and rural residents, the ratio of income of urban and rural residents will be 4.61 in 2015 and 4.8 in 2020, following the changes in urban-rural gap over the last decade. Statistics in 2008 show that the gap of per capita income between urban and rural residents grew by 40\% compared to that in 1997.

In the BAU scenario, energy consumption in China will see remarkable growth. The proportion of industry and the economic growth rate will remain at a high level for some time. Therefore, per capita energy consumption, which was 1.23 tons of standard coal per 10,000 RMB production value, will continue to decrease to 0.90 in 2020, although there is the potential for higher energy efficiency. Aggregate energy consumption, however, will increase from 6.624 billion tons in 2007 to 12.8 billion tons in 2020 . According to the BAU scenario, from 2005 to 2020, greenhouse gas emission per unit of GDP will decrease from 3.07 tons per 10,000 RMB to 2.05 tons per 10,000 RMB with emission intensity cut by $33 \%$. That means that according to the current trend of economic development, the growth of this type will be unsustainable as energy supply and the pollution that follows will far exceed China's resources and environmental carrying capacity with growing aggregate demand for energy.

The simulation results of the BAU scenario show that deeply rooted problems in economic operation will not be solved if China follows the past development model. Problems like imbalanced, uncoordinated, and unsustainable economic development will be increasingly prominent. Some prominent problems include the imbalanced relationship between consumption and investment, imbalanced industrial development, a growing income gap, high energy consumption, and intense pollution. The economy is vulnerable to risks with this development model. Without further reform, the problems will continue and it will remain uncertain whether China will be capable of leaping over the middle-income trap to achieve a high-income society.

\section{An analysis of the accelerated reform scenario}

Compared to the BAU scenario, the accelerated reform scenario shows significant differences in terms of sources of growth, the industrial structure, energy, and the environment as detailed in the following aspects. 
First, economic growth will not overly rely on a high investment rate. With the acceleration of reform, the growth rate during the 12th Five-Year Plan period will be 0.5 percentage points higher than that in the BAU scenario. The general growth rate is also slightly higher than the BAU scenario from 2015 to 2020. It is even more prominent that the sources of GDP growth, against the backdrop of accelerated reform, undergo essential changes. Growth, which was generally driven by high investment, will be driven by both investment and better technology and efficiency, with a higher contribution from technology, which addresses the requirement of sustainable development and shows another important feature of the change of the development pattern. The simulation results show that nearly $40 \%$ of GDP growth will come from TFP improvement by 2020. The TFP improvement gives a full view of technological innovation, better efficiency of production, and energy and resource use, all of which will be attributed to the driving force of reform.

Second, the industrial structure will tend to be more optimized. Compared with the BAU scenario, the service sector will account for a bigger proportion under accelerated reforms. By the end of 12th Five-Year Plan, the tertiary industry will account for $45.7 \%$, 1.7 percentage points higher than that under the BAU scenario, while its proportion will reach 50.0\%, 3.4 percentage points higher than that under the BAU scenario. With changes to the industrial structure, the structure of the labor force and employment will also undergo changes accordingly. The proportion of employment in the tertiary industry will increase in different periods, 2.2 percentage points higher by 2015 and 4.2 percentage points higher by 2020. Rapid development of the service sector will bring job opportunities to the rural labor force, which will accelerate the transfer of the labor force from rural to urban areas and boost urbanization.

Third, the structure of investment, consumption, and exports will be more balanced. With accelerated reform, the government will strengthen the establishment of social and housing welfare with an increase of government expenditure from the level in the BAU scenario. The proportion of government expenditure will be 0.6 percentage points higher than the BAU level by 2015 and 1.1 percentage points higher by 2020 . With the social welfare system in better shape, the savings demand will decrease from the BAU level. By 2015, consumption will account for $51 \%, 5$ percentage points higher than the BAU level. However, investment will decrease by 3.3 percentage points from the BAU level by 2015 and 3.5 percentage points by 2020. This shows that consumption will play a bigger role in driving the economy under accelerated reforms, with the three types of demands more balanced and citizens benefitting more from economic growth. This reflects another important feature of the change to the development model in terms of demand. Economic development, which mainly has relied on investment and exports, will be driven by the 'trifecta' - investment, consumption, and exports, especially consumption. The adjustment plays an important role in maintaining the long-term potential for growth of the Chinese economy and reducing the influence of changes in the international economy on the Chinese economy.

Fourth, the income of urban and rural residents will increase more rapidly and the income gap will narrow. On one hand, against the backdrop of accelerated reform, the service sector and small- and medium-sized companies will enjoy more rapid growth with unreasonable restrictions on the service sector being canceled, which will increase urban demand for labor. It will create conditions for labor force transfer from rural to 
urban areas in terms of demand and will play an important role in narrowing the gap of marginal productivity between agricultural and non-agricultural industries. On the other hand, the structural adjustment of public expenditure will raise rural income levels and educational and occupational quality, creating conditions for the transfer of the labor force to urban areas. These factors working together will result in a more rapid increase of income for urban and rural residents with a narrowing income gap. With accelerated reform, the income of urban and rural residents will increase by 10 percentage points to $20 \%$ from the BAU level, while the income ratio of urban and rural residents will decrease by 5 percentage points to $10 \%$ from the BAU level. Apart from that, the consumption structure will undergo faster upgrading with higher incomes and the accelerated development of the service sector.

Fifth, resources will be conserved and damage to the environment reduced. Accelerated reform will follow reform to resources and environment taxes and the energy price where the price of energy and resources will fully reflect its production cost and the external influence. This will improve the efficiency of energy use and ultimately benefit energy savings and emission reduction. In the meantime, the optimized structure of industries and expenditure will also play a very important role in energy savings and emission reduction. The factors working together will bring changes to the model of economic development, which has focused solely on economic growth and will now attach more importance to the coordinated development of the economy, resource, and the environment. Compared with the BAU scenario, the total volume of energy consumption will decrease by $14 \%$ by the end of the 12th Five-Year Plan period and $25 \%$ by 2020 . With regard to greenhouse gas emissions, $\mathrm{CO}_{2}$ emissions will decrease by $19 \%$ by 2015 and 33\% from the BAU level by 2020 .

\section{Conclusion}

Looking into the prospects of China's economic development in the next decade, the positive momentum of the Chinese economy will remain unchanged, while the main driving forces for the sustainable and rapid growth of the Chinese economy will continue. However, it must be noted that China is a big developing country that is open and closely connected to the world economy. The development of China does not only depend on domestic factors but also lies in the international environment. In the next decade, China will face a more complicated international environment with more uncertainties compared to the last 10 years. The global economy will undergo twists and turns in its road to recovery, with lingering effects from the global financial crisis, and enter a period of moderate- or low-speed growth. International protectionism will gain ground and have adverse effects on China's external demands. In the meantime, with stronger economic power and higher international status, China will be faced with higher expectations and demands from the international community for its fulfillment of international responsibilities and obligations. In the meantime, while developing into a high-income country from an upper middle-income country, China will also be faced with a series of challenges like an aging population, rising cost of factors of production, urgent need for upgrading the industrial structure, outstanding social contradictions, and stronger constraints from resources and the environment. 
According to our simulation analysis of the prospects of China's economic development in the next decade, the deeply rooted problems in China's economic operation will not be solved if it follows the past development model. Problems like imbalanced, uncoordinated, and unsustainable economic development will be increasingly prominent. Some prominent problems include the imbalanced relationship between consumption and investment, imbalanced industrial development, the growing income gap, high energy consumption, and intense pollution. If further reform is promoted in factors of production, public expenditures, energy, and the environment based on the reform in the past 30 years, China will not only mitigate and solve these deeply rooted problems that are increasingly prominent in economic development, but also stimulate the internal power of the economy for long-term sustainable and coordinated development. According to our simulation results, China's economy will not only maintain a relatively high growth rate, but also generate more sustainable power with an optimized industrial structure and a more coordinated consumption-investment structure and urban-rural relationship while energy is better conserved and the environment less affected.

Competing interests

The authors declare that they have no competing interests.

\section{Authors' contributions}

LS conceived the study and drafted the 'conclusion' part (the last part). WS drafted the 'international and domestic environment' part (the first and second part). HJ drafted the 'China's development prospect' part (the third part). All authors read and approved the final manuscript.

\section{Authors' information}

LS is a senior research fellow and former director general of the Department of Development Strategy and Regional Economy of Development Research Center (DRC) of the State Council (People's Republic of China). She was a member of the National Committee of CPPCC. She is also vice president of the Academic Committee of the China Development Research Foundation. She has ever played a key role in several national key projects for China's economic development and joint development projects with the World Bank, UNDP, UNIDO, OECD, and the ADB. She became vice director of the Bureau of Development and Forecasting of DRC in 1990 and director of that Bureau in 1995. She is the vice president of the International Input-output Association from 2001 up to now.

WS is an associate professor of the School of Humanities and Economic Management in the China University of Geosciences.

$\mathrm{HJ}$ is an associate research fellow at Development Research Center of the State Council.

\section{Acknowledgement}

This article is sponsored by the China Development Research Foundation's project 'China's 10-year Progress in WTO'.

\section{Author details}

'Department of Development Strategy and Regional Economy, Development Research Center of the State Council, No. 225, Chaonei Dajie, Beijing 100010, China. ${ }^{2}$ School of Humanities and Economic Management, China University of Geosciences, Beijing 100083, China.

Received: 10 September 2012 Accepted: 8 November 2013

Published: 23 December 2013

\section{References}

Hu A et al (2011) Ten years since China's accession to WTO: review and prospects (中国入世十周年:总结与展望) Int Econ Rev (国际经济评论) 5:40-83

Li S et al (2011) Chinese economy in 2030 (2030年的中国经济). Economic Science Press (经济科学出版社), Beijing

Li S, He J, Hu F, Zhang S (2010) Quantitive analysis of the effects of foreign trade on the economic and social development of China (外贸对我国经济社会发展作用的定量分析). Rev Econ Res (经济研究参考) 9:3-4, +30

Long G (2011) Ten years since China's accession to WTO: new starting point (中国入世十周年:新的起点). Int Econ $\operatorname{Rev}$ (国际经济评论) 4:103-113, +5

Lu Z (2010) International environment of the economic and social development of China in $12^{\text {th }}$ Five-Year Plan period (“十二五” 期间我国经济社会发展的国际环境). Qiushi (求是) 23:24-26 
Pei C, Yang Z (2011) Ten years since China's accession to WTO and international and domestic environment of multi-trade governance (中国入世十年与多边贸易治理的内外环境). China Econ Trade Herald (中国经贸导刊) 6:13-16

Research Group on the Analysis and Application of Input-output Table of China in 2007 (2011) China's economic prospect for the 12th Five-Year Plan Period and 2030 ( “十二五” 至2030年我国经济增长前景展望). Stat Res (统计研究) 1:5-10

doi:10.1186/2196-5633-1-5

Cite this article as: Li et al:: Prospects for China's economic development in the next decade. China Finance and Economic Review 2013 1:5

Submit your manuscript to a SpringerOpen ${ }^{\odot}$ journal and benefit from:

- Convenient online submission

- Rigorous peer review

- Immediate publication on acceptance

- Open access: articles freely available online

- High visibility within the field

- Retaining the copyright to your article 